\title{
ASSESSMENT OF ORTHODONTIC TREATMENT STANDARD IN FACULTY OF DENTISTRY, UNIVERSITY OF MALAYA
}

B.L. Leong, N. Zamzam, Z. Yassin, R. Abdul Kadir. Assessment of orthodontic treatment standard in Faculty of Dentistry, University of Malaya. Annal Dent Univ Malaya 2001; 8: 25-28.

\section{ABSTRACT}

The aim of this study is to evaluate the treatment outcome using fixed and removable appliances, in the Faculty of Dentistry, University of Malaya (U.M.). The study models of 25 fixed and 30 upper removable appliance cases, with complete written records were examined before and after orthodontic treatment using the PAR (Peer Assessment Rating) Index. All the data were analyzed using the Statistical Package for Social Sciences (SPSS) for Windows. Eighty five percent of the cases selected as sample were either 'improved' or 'greatly improved'. Among the 10 cases which were 'greatly improved', all had high pre-treatment PAR points ( $>35$ PAR points). Conversely, all the eight cases classified as 'worse or no different' were with low pretreatment PAR scores ( $<20$ PAR points). The mean treatment duration in this study was 23.1 months, ranging from 2 months to 78 months. The results of this study showed that the standard of treatment in this Faculty were fairly acceptable.

Key words: Treatment standard, PAR Index

\section{INTRODUCTION}

The grading of orthodontic treatment results at study group meetings has been practiced for a long time (1). Unfortunately, it is difficult to compare the results, as there are too many variations in the criteria used. In order to overcome these difficulties, a series of six meetings with a group of 10 experienced orthodontists was convened (1). Over 200 study casts were discussed until agreement was reached regarding individual features considered to be important in obtaining an estimate of malocclusion. Consequently, a scoring system was developed (2), namely the PAR Index that provided a single summary for all the occlusal anomalies. Validity of this index was improved by assigning weightings to each component to reflect current British Orthodontic Opinion (3) and provided a new weighted PAR total score that is the final form in which the index was introduced.

In this study, the standard of fixed and removable appliance treatment, as measured by PAR Index and the average duration of treatment of both appliance therapies were evaluated. However, all the results should be interpreted with caution due to the small number of samples and the methods of sample selection used,
Original Article

B. L. Leong ${ }^{1}$, N. Zamzam² ${ }^{2}$ Z. Yassin ${ }^{2}$ and

R. Abdul Kadir ${ }^{3}$

${ }^{1}$ General Dental Practitioner, Kuala Lumpur

${ }^{2}$ Orthodontic Lecturer,

Department of Children's Dentistry \& Orthodontic,

Faculty of Dentistry, University of Malaya,

50603 Kuala Lumpur

${ }^{3}$ Professor, Department of Community Dentistry,

University of Malaya, 50603 Kuala Lumpur

Corresponding author - Norzakiah Mohamed Zamzam

which only depend on the availability of complete written records.

\section{MATERIALS AND METHODS}

\section{Materials}

The material for this study included pre- and posttreatment study models that had been treated completely in the orthodontic department of U. M. between January 1984 and June 1996. Only patients with complete preand post-treatment study casts and written treatment records were included. Damaged, unnamed, unnumbered and undated cases were excluded. Sets of study models obviously trimmed in incorrect jaw relationship also were excluded. No orthognathic surgery patients were enrolled in this study. According to the above criteria, 25 fixed and 30 upper removable appliance cases were chosen. The cases had been treated completely by academic staff and undergraduate students with direct supervision by the academic staff in the orthodontic department. Out of these 55 cases, (with a total of 110 study models), 39 were female and 16 were male, with age ranged from 9 to 33 (Table 1).

Table 1: Patients' gender and appliance types

\begin{tabular}{|c|c|c|c|c|c|}
\hline & & & URA & FA & Total \\
\hline \multirow[t]{2}{*}{ Gender } & Female & $\begin{array}{l}\text { Count } \\
\% \text { of Total }\end{array}$ & $\begin{array}{l}19 \\
34.5 \%\end{array}$ & $\begin{array}{l}20 \\
36.4 \%\end{array}$ & $\begin{array}{l}39 \\
70.9 \%\end{array}$ \\
\hline & Male & $\begin{array}{l}\text { Count } \\
\% \text { of Total }\end{array}$ & $\begin{array}{l}11 \\
20.0 \%\end{array}$ & $\begin{array}{l}5 \\
9.1 \%\end{array}$ & $\begin{array}{l}16 \\
29.1 \%\end{array}$ \\
\hline Total & & $\begin{array}{l}\text { Count } \\
\% \text { of Total }\end{array}$ & $\begin{array}{l}30 \\
54.5 \%\end{array}$ & $\begin{array}{l}25 \\
45.5 \%\end{array}$ & $\begin{array}{l}55 \\
100.0 \%\end{array}$ \\
\hline
\end{tabular}

URA-removable appliance

FA-fixed appliance 


\section{Methods}

Unweighted scores for the 11 elements of PAR index (2), were recorded with a single PAR ruler throughout the measuring of all pre- and post-treatment study cast in order to eliminate the effect of any variation possibly present between different rulers. The individual scores for each PAR component were multiplied by the weightings accordingly and then summed to establish the overall total PAR score. Both pre- and post-treatment total PAR score were calculated, weighted and recorded using the PAR score recording form. TH a difference between pre-treatment PAR score and post-treatment PAR score was calculated for each case and it reflected the success or degree of improvement (4). The percentage change in PAR score was also calculated.

\section{Error study}

Inter- and intra-examiner agreements were carried out to assess the reliability in measurement of PAR Index in this study.

\section{Inter-examiner agreement}

For inter-examiner agreement, a subsample of five cases of patients treated with fixed appliances was selected. All the 11 components of the PAR Index were measured on a total of 10 study models by two examiners, which evaluated the level of agreement between the subjective rankings of malocclusion.

\section{Intra-examiner agreement}

To confirm reliability in this study, the same subsample of cases that used in the Inter-examiner Reliability study were reassessed one week later by the same examiner without reference to the original results. Both studies were evaluated by the percentage agreement and Kappa statistics of measurement error (5).

\section{RESULTS}

\section{Error study}

Both inter- and intra-examiner agreement of the PAR Index showed a very good Kappa agreement $(\mathrm{k}=1)$ with $100 \%$ agreement. Therefore, the measurement of PAR Index in this study was reliable (Table 2).

\section{Treatment outcome}

In this study, the unweighted mean pre-treatment PAR score was 12.4 (standard deviation (S.D.) = 3.9)

Table 2: Value for kappa $(k)$ and the strength of agreement

\begin{tabular}{lc}
\hline Value of $k$ & Strength of agreement \\
\hline$<0.20$ & Poor \\
$0.21-0.40$ & Fair \\
$0.41-0.60$ & Moderate \\
$0.61-0.80$ & Good \\
$0.81-1.00$ & Very good \\
\hline
\end{tabular}

and the weighted mean pre-treatment PAR score was 28.4 (S.D. = 8.6) (Table 3). The unweighted mean posttreatment PAR score was 6.5 (S.D. $=2.4$ ) and the weighted mean post-treatment PAR score was 13.2 (S.D. =6.1) (Table 3) while the mean change in weighted PAR score was 15.2 (Table 3 ). On the other hand, the mean percentage change in PAR score was $47.5 \%$ (S.D. $=25.6 \%$ ) (Table 3). According to the nomogram classification of improvement, $67.3 \%$ of the total cases at least 'improved' after treatment, with $18.2 \%$ of the cases being "greatly improved" and having only $14.5 \%$ of the cases being 'worse or no different' after orthodontic intervention (Figure 1).

Table 3: Treatment outcome for overall sample

\begin{tabular}{lccc}
\hline & N & Mean & SD \\
\hline Weighted Pre-treatmentPAR score & 55 & 28.4 & 8.6 \\
Unweighted Pre-treatment PAR score & 55 & 12.4 & 3.9 \\
Weighted Post-treatmentPAR score & 55 & 13.2 & 6.1 \\
Unweighted Post-treatment PAR score & 55 & 6.5 & 2.4 \\
Change in weightedPAR score & 55 & 15.2 & 9.9 \\
Percentage PAR change (\%) & 55 & 47.5 & 25.6 \\
\hline
\end{tabular}

$\mathrm{N}$-number of samples

SD-standard deviation

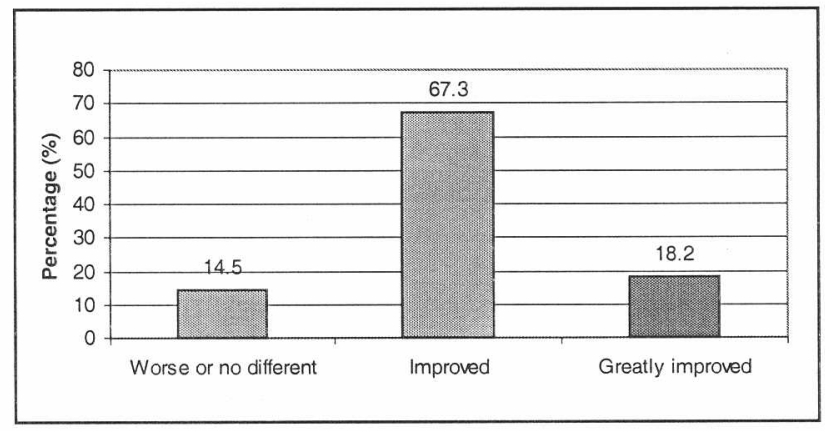

Figure 1: Classification of improvement

\section{Duration of treatment}

On average, the length of time taken to complete treatment was $23.1 \pm 16.2$ months, with a shortest duration of two months and the longest exceeded 78 months. The shortest duration of two months involved treatment with an upper removable appliance to correct a single tooth in crossbite.

\section{DISCUSSION}

The pre-treatment PAR scores was a good predictor of both treatment result and long-term outcome since the higher the pre-treatment PAR scores, the easier it was to achieve the 22 points reduction needed for a 'greatly 
improved' result. The mean pre-treatment PAR scores was 28.4 (S.D. = 8.6), which was comparable with the value of other studies $(6,7,8,9)$, ranging from 26 (6) to 30 (9). In this study, it was shown that all of the five cases with a pre-treatment PAR scores of greater than 40 demonstrating a greatly improved treatment outcome.

The mean post-treatment PAR score (unweighted) in this study was less than 10. Generally, a PAR score of 10 or less indicates an acceptable alignment and occlusion, and a score of 5 or less suggested an almost ideal occlusion, whereas a score of 0 , which indicates ideal occlusion and alignment, is almost impossible (2). Thus it was shown that orthodontic patients here were treated to an acceptable occlusion and alignment. Birkeland et al., (10) revealed that post treatment ideal occlusion (a low post-treatment PAR score) is important for a good long-term result of orthodontic treatment. However, Kelly and Springate (6) showed that in view of limitations of PAR Index, a low post-treatment PAR score was not of a guarantee of high standard of treatment. Richmond et al., (4) revealed that to consider a case as 'greatly improved', a score reduction of at least 22 points was required. Thus, the average change of 15 PAR point in this study indicated that cases treated in Faculty of Dentistry, U.M. were not 'greatly improved'

A $30 \%$ reduction in the weighted PAR scores was required for a case to be 'improved' and a high standard of treatment required the mean percentage reduction of greater than $70 \%$. On the whole, the mean percentage reduction in PAR score of $47.5 \%$ indicated that treatment with removable and fixed appliances in Faculty of Dentistry, U.M. were at least 'improved'. This value was generally lower than those found in other studies, ranging from $55.4 \%$ (11) to $89.0 \%$ (6). However, great caution must be exercised when comparing the two studies due to the distinct difference in their study design.

Treatment standard was considered high if the proportion of cases falling into the 'worse or no different' category should be negligible (4), and ideally less than $5 \%(9)$, along with a high mean reduction in PAR scores of greater than $70 \%$ and a high percentage of cases that had been 'greatly improved' should be greater than $40 \%$ (4). According to this, it could be concluded that the treatment standard in the Faculty of Dentistry, U.M. was fairly acceptable.

The mean for duration of active treatment in this study is comparable with the length of time taken by a teaching school in Norway to complete treatment, which ranged from 24 months to 25 months on average. In contrast, shorter mean treatment duration was reported in other studies, ranging from two months (12) to 18.3 months (11). The reason for longer treatment duration found in this study may be due to malocclusion severity, treatment involving extraction, breakage or repair of appliances and the number of missed appointments, as well as the delay between change of appliance for cases needed more than one appliances in upper removable appliance therapy that were carried out by undergraduate students. However, the duration of treatment time do not influence the level of treatment standard.
This study has several limitations that are primarily due to the retrospective design; the measure of treatment success was being confined to the assessment of treatment in a teaching hospital. These shortcomings are primarily concerned with bias that has arisen from factors that determined the selection of subjects whereby all the cases being chosen had to have complete written records.

\section{CONCLUSIONS}

From the results of this study, it could be concluded that on the whole, cases treated in Faculty of Dentistry, U.M. were treated to an acceptable occlusion and alignment as indicated by the mean post-treatment PAR score $(6.45$ PAR points). $67.3 \%$ the total sample become 'improved', $18.2 \%$ of the sample become 'greatly improved', and $14.5 \%$ percent of the sample remained in the 'worse or no different category' after treatment. On average, the mean duration of time taken to complete fixed and removable appliances therapy in Faculty of Dentistry, U.M. was 23.1 months. A wide range of treatment duration could be seen, as indicated by the shortest duration of 2 months to the longest duration of 78 months.

\section{ACKNOWLEDGEMENTS}

We gratefully acknowledge Dr. Teh Leok Hui and Dr. M. Shafeeq Hasan for their invaluable assistance.

\section{REFERENCES}

1. British Orthodontic Standards Working Party $2^{\text {nd }}$ Report. Br J Orthod 1986; 165-173.

2. Richmond S, Shaw WC, O' Brien KD, Buchannan IB, Jones R, Stephens CD, Roberts CT and Andrews M. The development of the PAR Index (Peer Assessment Rating): Reliability and validity. Euro J Orthod 1992a; 14: 125-139.

3. Richmond SR, 1989. A question of standards presented at the British Orthodontics Conference.

4. Richmond S, Shaw WC, Robert CT and Andrews M. The PAR Index (Peer Assessment Index): Methods to determine outcome of orthodontic treatment in terms of improvement and standards. Euro J Orthod 1992b; 14: 180-187.

5. Bland JM and Altman DG. Statistical methods for assessing agreement between two methods of clinical measurement. 1986 Lancet I: 307-310.

6. Kelly BM and Springate SD. Specialist orthodontics in the GDS. Br Dent J 1996; 180: 209-215. 
7. O' Brien KD, Shaw WC and Roberts CT. The use of occlusal indices in assessing the provision of orthodontic treatment by the hospital orthodontics service of England and Wales. Br J Orthod 1993; 20: $25-35$.

8. Fox NA. The first 100 cases: A personal audit orthodontic treatment assessed by the PAR (Peer Assessment Rating) Index. Br Dent J 1993; 174: 290-297.

9. Richmond S, Andrews M and Robert CT. The provision of orthodontic care in the GDS of England and Wales: extraction patterns, treatment duration, appliance types and standards. Br J Orthod 1993; 20: 345-350.
10. Birkeland K, Furevik J, Boe OE and Wisth PJ. Evaluation of treatment and post-treatment changes by the PAR Index. Euro J Orthod 1997; 19: 279288 .

11. Taylor PJS. A study of factors associated with orthodontic treatment outcome. University of Glasgow, 1992. MSc Thesis.

12. Leok-Hui Teh. Orthodontic treatment with fixed appliances in the General Dental Service of Scotland. University of Glasgow, 1998. MSc Thesis. 